\title{
THE NATURAL HISTORY OF HOOKED FOREFOOT
}

\author{
G. F. RUSHFORTH \\ From Queen Mary's Hospital for Children, Carshalton, Surrey
}

\begin{abstract}
This paper reports on a prospective study undertaken to determine the natural history of untreated idiopathic hooked forefoot. The progress of $\mathbf{1 3 0}$ affected feet in eighty-three children was followed for an average of seven years. At review 86 per cent of the feet were normal or only mildly deformed and all were fully mobile; 10 per cent were still moderately deformed but were asymptomatic; 4 per cent remained deformed and stiff. It was not possible to detect these resistant cases before the age of three years, but the low failure rate would seem to justify a policy of expectant treatment.
\end{abstract}

That hooked forefoot (metatarsus varus) undergoes spontaneous correction with time has been postulated previously. The present study was undertaken to test this view. This interim paper reports the progress of a group of children collected from 1965 over an eleven-year period. The abnormality is usually noticed at birth or within the first three months of life although sometimes it does not become apparent until later. The forefoot is noted to be concave on its inner border often with a marked midtarsal crease. The outer border is convex but the heel appears normal. In most feet the deformity can be corrected to neutral although not into a position of "over correction" as in the normal foot (Figs. 1 and 2). By definition the infant is otherwise normal.

\section{METHOD AND MATERIALS}

All the children were under one year of age when seen initially, and any with abnormality of the neuromuscular system was excluded. A diagnosis of idiopathic hooked forefeet was made on 156 children over the period of this study, of whom 116, with 179 affected feet between them, have been available for review. One hundred and ten children were examined personally, and a further six included after correspondence with their parents. At the initial examination, the feet were photographed with the children held in a standing position. These records permitted a grading into mild, moderate and severe, of which examples are shown in Figures 1, 3 and 4 . This visual grading is presented in Table I; it can be seen that children with more severely deformed feet were brought for attention early. Of the fifty-five affected feet recognised at birth, 85 per cent were moderately to severely affected, but of the ninety-two affected feet recognised at six to twelve months, only 62 per cent were comparably severe. The ability to correct the forefeet by passive stretching was considered essential to the diagnosis of uncomplicated hooked forefoot. Radiographs were not taken since the limited information obtained was not felt to justify the investigation. This series included eight West Indians and one Asian. There was a slight male predominance of sixty-five boys to fifty-one girls, a ratio of $1.3: 1$. No child had a neurological abnormality affecting muscle tone or control, although one child developed epilepsy following meningitis and was mentally subnormal. Another child had a congenital dislocation of her hip.

Table I. Comparison of the age at which the condition was noted and the degree of deformity as assessed from the photographs taken when the children were first seen

\begin{tabular}{|l|rl|rr|rr|rr|}
\hline & \multicolumn{2}{|c|}{ Birth } & 3-6 months & 6-12 months & \multicolumn{2}{|c|}{ Total } \\
\hline Mild & 8 & $15 \%$ & 7 & $22 \%$ & 35 & $38 \%$ & 50 & $28 \%$ \\
Moderate & 25 & $45 \%$ & 18 & $56 \%$ & 49 & $53 \%$ & 92 & $52 \%$ \\
Severe & 22 & $40 \%$ & 7 & $22 \%$ & 8 & $9 \%$ & 37 & $20 \%$ \\
\hline $\begin{array}{l}\text { Affected } \\
\text { feet }\end{array}$ & 55 & 32 & 92 & \multicolumn{2}{|l|}{179} \\
Children & 35 & 25 & 56 & 116 \\
\hline
\end{tabular}

\section{RESULTS}

The children's ages varied at review from one to eleven years. Their feet were examined for mobility and a visual assessment made of residual deformity in comparison with their original photographs. Normal feet had no residual deformity or stiffness, with a neutral heel. Figure 5 shows a child aged four and a half years with normal feet whose original deformity, assessed as moderate, is shown in Figure 1. Those with persistently deformed feet were compared with their original photographs, and were assessed as mild, moderate or severe residual deformities.

Of the children in their second and third year of life, two feet had already become normal and the degree of severity of the remainder was decreasing. In the group of eighty-three children aged three years or more, eighty-

G. F. Rushforth, F.R.C.S., Senior Orthopaedic Registrar, Queen Mary’s Hospital for Children, Carshalton, Surrey SM5 4NR, England. 


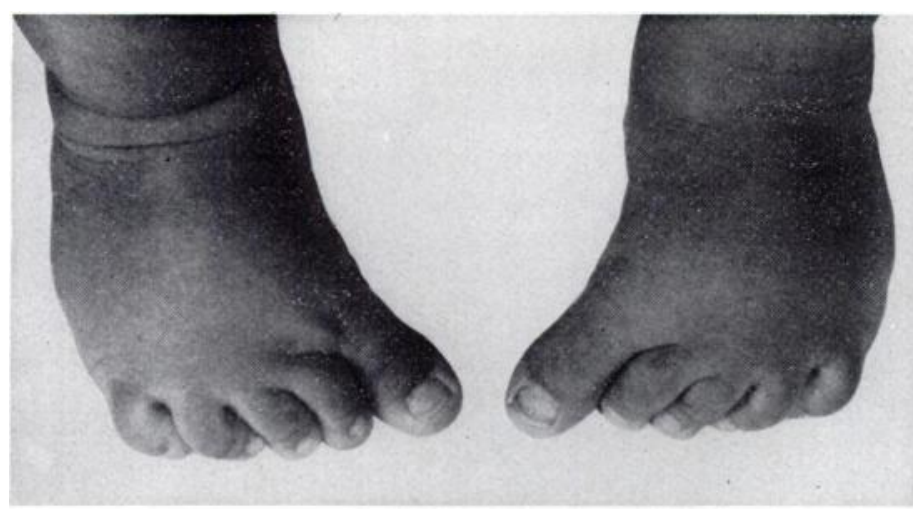

Fig. 1

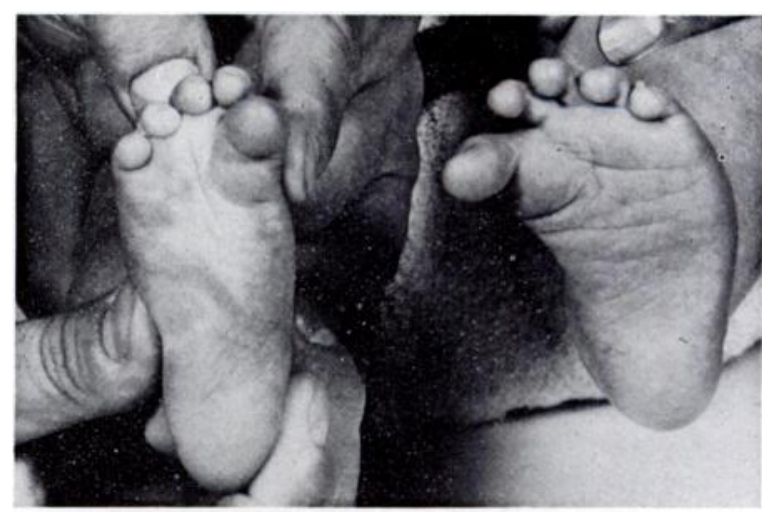

Fig. 2

Figure 1-An example of hooked forefeet. Boy aged ten months, graded as moderate, shown four years later in Figure 5. Figure 2-Correction could be obtained to "neutral" in all feet. This child's feet are seen in the standing position in Figure 4, and graded as severe.

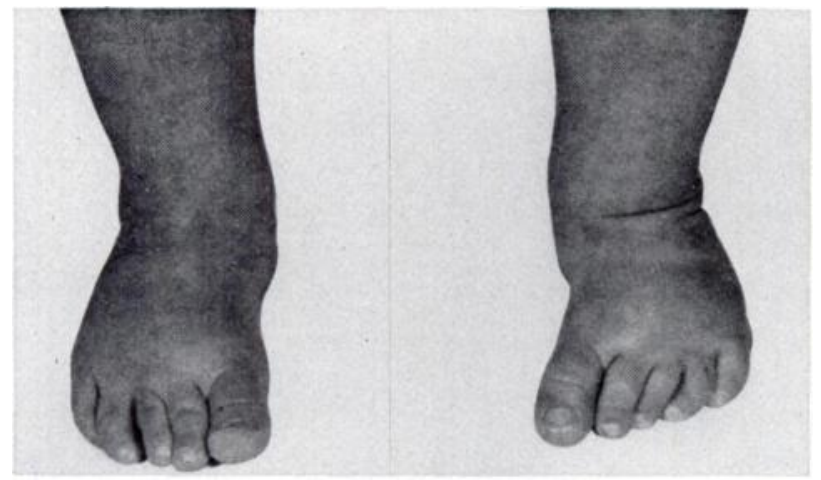

Fig. 3

An eight-month-old child with mild deformity on the left and moderate on the right.

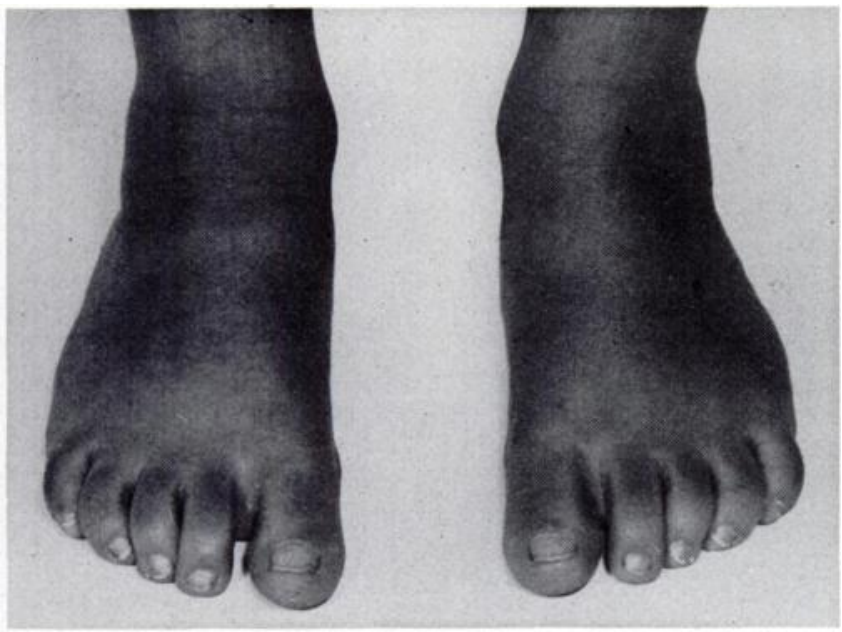

Fig. 5

The child in Figure 1 at the age of four and a half years, showing complete correction.

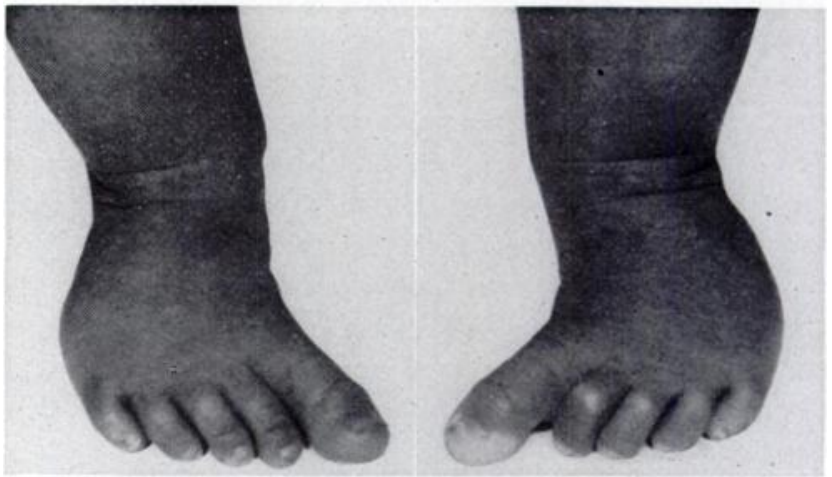

Fig. 4

Bilateral severe deformity at the age of six months. (Seen corrected in Fig. 2).
INITIAL CLINICAL ASSESSMENT

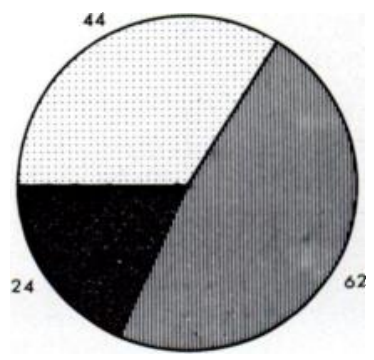

AFFECTED FEET

130
AT REVIEW

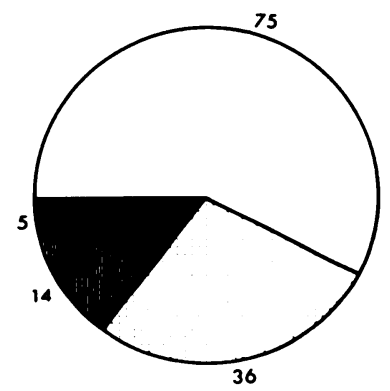

Number of Children

83

Moderate

Severe
Fig. 6

A diagrammatic presentation of the initial assessment and the findings at review, for children aged three to eleven years. 
six per cent had normal or only mildly affected feet as compared with their original photographs. This improvement is demonstrated in Figure 6 where the initial clinical assessment of this group of children is compared with the findings at review.

\section{DISCUSSION}

Henke (1863) was probably the first to describe the condition and Cramer $(1904,1906)$ reported four further cases. The first reference in the English literature was by Bankart (1921) who observed that although the condition was familiar to clinicians, its separate entity was denied by current orthopaedic textbooks which usually classified it as a "forme fruste" of club foot. Madier and Massart (1923) provided a full description referring to the forefoot deformity as "pes adductus" and differentiating this from a resistant variant which they called metatarsus varus. Peabody and Muro (1933) preferred metatarsus adductus to describe a residual deformity in club foot persisting after correction of the hindfoot, whereas Kite (1950) reserved the same term for the severe deformity resisting treatment, using metatarsus varus for the more common condition which is easily corrected. Subsequent papers have concentrated on treatments which have been variable. The possibility of spontaneous correction in most children was suggested by Ponseti and Becker (1966) who felt that only 11.6 per cent of their patients required treatment. This confusion in nomenclature necessitated simplification and for this reason the term hooked forefoot has been adopted. In this study, idiopathic hooked forefoot has been shown to correct spontaneously in the majority of children by the age of three years.

Possible aetiological factors were investigated. It was noted that the one child with a congenital dislocation of the hip had a sister with paralytic spina bifida and that another child's grandfather had had
Charcot-Marie-Tooth disease, but our patient showed no evidence of this himself.

Genetic factors play a part. Five children had siblings with hooked forefeet and in a further twentyfour one or other parent was said to have had a similar deformity in childhood, but all had corrected spontaneously. Four children had siblings with club feet, one a father and one a cousin. The incidence of first-degree relatives with club foot was 4.3 per cent compared with Wynne-Davies's (1964) figure of 2.9 per cent. There was no evidence of intra-uterine factors being of aetiological significance. The maternal age when the children were born ranged from fifteen to thirty-six years, with a mean of twenty-seven years, and half the children were second born. Nearly half were full-term gestations, with an equal proportion of premature and postmature deliveries. If intra-uterine pressure were a factor it was felt that more would have been born either to younger mothers or to elderly primigravidae, and that the majority would have been first born.

We do not know what will happen to the nineteen feet, in fourteen children, which failed to correct by the age of four. These children remain under observation and it is hoped that a further report will be presented later. There is a suggestion that in some of this group, the adduction is mainly of the first metatarsal ray; these may develop adolescent hallux valgus later. We were unable to predict these failures with certainty before three years of age. We also do not know whether these failures would have been improved by closed methods of treatment, or even by early open correction as with clubbed feet.

These questions need to be answered by further study. However, the low incidence of failure with expectant treatment seems to justify the present policy. All the children with persistent deformity were free of symptoms, but the parents of the girls did express concern at the cosmetic implications.

I would like to express my profound gratitude to Mr Geoffrey Walker and the orthopaedic secretaries at Queen Mary's Hospital for Children, Carshalton. I have received considerable help from both the Photographic Department of that hospital and that of St George's Hospital, Tooting.

\section{REFERENCES}

Bankart, A. S. B. (1921) Metatarsus varus. British Medical Journal, 2, 685.

Cramer, K. (1904) Metatarsus varus congenitus. Archiv für Orthopädie, Mechanotherapie und Unfallchirurgie, 2, 370-374.

Cramer, K. (1906) Ein Fall von Metatarsus varus congenitus. Archiv für Orthopädie, Mechanotherapie und Unfallchirurgie, 4, $384-387$.

Henke, W. (1863) Contractur des Metatarsus. Zeitschrift für Rationelle Medizin, 17, 188-194.

Kite, J. H. (1950) Congenital metatarsus varus. Journal of Bone and Joint Surgery, 32-A, 500-506.

Madier, J., and Massart, R. (1923) Etude anatomique du metatarsus varus congénital. Bulletins et Mémoires de la Société Anatomique de Paris. 6th Series, 20, 119-132.

Peabody, C. W., and Muro, F. (1933) Congenital metatarsus varus. Journal of Bone and Joint Surgery, 15, 171-189.

Ponseti, I. V., and Becker, J. R. (1966) Congenital metatarsus adductus. Journal of Bone and Joint Surgery, 48-A, 702-711.

Wynne-Davies, R. (1964) Family studies and the cause of congenital club foot. Journal of Bone and Joint Surgery, 46-B, 445-463. 